\title{
STATIC FATIGUE ANALYSIS ON THE LOAD CONTAINER OF A LOW-COST VEHICLE FOR NIGERIAN RURAL FARMERS
}

\author{
S. A. Yahaya ${ }^{1, *}$ and K. O. Abdulrahman ${ }^{2}$ \\ 1, DEPARTMENT OF BIOMEDICAL ENGINEERING, UNIVERSITY OF ILORIN, ILORIN, KWARA STATE, NIGERIA \\ 2, DEPARTMENT OF MECHANICAL ENGINEERING, UNIVERSITY OF ILORIN, ILORIN, KWARA STATE, NIGERIA \\ E-mail addresses: ${ }^{1}$ yahaya.say@unilorin.edu.ng, ${ }^{2}$ abdulrahman.ko@unilorin.edu.ng
}

\begin{abstract}
Static fatigue analysis was done on the container of a model low cost vehicle for Nigerian rural farmers to determine how well the container has been designed and its resistance to notable deformation or damage, based on the load it was subjected to. The static analysis performed involved the fixing of the container in areas where it is made to rest on the chassis. Finite element analysis of the vehicle container was conducted in two loading conditions. The result from the analysis gave a factor of safety of 4.36 for the load container at a maximum displacement of $0.131 \mathrm{~mm}$ and a factor of safety of 4.65 for the load container and a maximum displacement of 0.136 respectively for the two loading conditions. These maximum displacements, which can be negligible shows that the load container is well designed as the maximum stresses are above the hand calculated maximum stresses.
\end{abstract}

Keywords: load container, static analysis, fatigue analysis, factor of safety, transportation, low cost vehicle

\section{INTRODUCTION}

Abdulrahman and Yahaya [1] modelled a low-cost vehicle for Nigerian rural farmers for transportation of farm produced. It was highlighted that farmers particularly face challenges of transportation during the postharvest period [2], [3]. The vehicle being a low-cost solution to meet the yearnings of the rural farmers of Nigeria was designed using locally available material and the load container, after due analysis, was recommended to be made of plywood readily available in the Nigerian Market. The plywood has a density within the range of $700-800 \mathrm{~kg} / \mathrm{m}^{3}$ with a price range of between $99.4-304 \# / \mathrm{kg}$ with moderate strength which made it suitable for the required purpose. The researchers selected this material based on form, density, availability in rural areas and price, with no test on the ability of the material to withstand the load it is to be subjected to. It is therefore appropriate to do a finite model analysis on the load container to confirm the appropriateness of the material and the geometry of the load container for possible design optimization. It is until researchers in Nigeria begin to take charge of design and optimization among others that, we can say a vehicle is truly manufactured in Nigeria [4].
However, not just manufacturing but meeting the social and economic needs of our community at the most minimal cost possible [5].

Zhuming [6] reported that the theory of finite element analysis (FEA) was sprouted from the needs of solving structural design problems in solid mechanics. FEA has been proven as a vital solution to a variety of design problems in solid mechanics. Mechanical design problems are classified as structural analysis, modal analysis, and fatigue analysis; they are formulated as FEA simulation models, so that commercial FEA tools can be applied to determine stress distribution, deformation, stability, and fatigue lives since measuring these items in an actual situation might be extremely difficult and costly [7].

Puckett [8] did a study on FEA stress analysis and outlined a respectable guide on the fundamental requirements and insight on how to start and optimise design using Finite Element Analysis (FEA) software. He evaluated the structural design of two stainless steel containment vessel for conformance to various design criterial. The two containment vessels were analysed for various loadings and structural assessment due to loading like pressure and 
temperature were presented. These analyses were performed using finite element structural analysis methods that was supplemented with some hand calculations. The COSMOS finite element analysis software was used in developing and solving the finite element model.

There are four rudimentary techniques involved in completing any basic finite element analysis, these are: assignment of geometry, application of boundary constraints and loads, defining the mesh of the object, and running the solver [9]. Abejide \& Okoro [10] used same steps in the analysis of the safety of carbon fibre reinforced plastic hollow section whilst under compression. Their columns of different sizes and material thicknesses were modelled using ABAQUS/CAE three-dimensional nonlinear finite element analysis and the results obtained were used to measure the deformation under compression.

Fahy \& Tiernan [11] developed a valid model of ISO tank that behaves in a comparable manner to the actual tank. The identified stresses that occur during standard tests were quantified. They used ANSYS 5.1 simulation software to give detailed steps in finite element modelling and analysis; identify area of high stress in the tank and support structure, quantify stresses and evaluate the safety factors. It was found that in area where historically tank failures occur (especially in the skirt) are particularly the areas of high stresses. The evaluation of the structural integrity of the machine design using finite element modelling tool is a great advantage for designers [12]. Reina [13] conducted an analysis on a bicycle frame making use of finite element method to ascertain the validity of finite element approach. The experiment proved the functionality, implementation and high accuracy of the finite element method vis-a-vis the experimental values. It was therefore concluded that the authenticity of the modelling methods and decisions employed greatly determines the finite element result [9].

It has been demonstrated that FEA can help verify the safeness of a design as demonstrated in the design of Portable tank and tank container for liquefied gas transportation, where FEA method was used to simulate the stress condition of the tank during utilization, enabling a comprehensive check to see whether every local structure of the said material meets the requirement of allowable stress on the material under loadings in accordance with relevant criterion and standards that eventually yielded a factor of safety of 3.0 [14].

The application of FEA method for optimization cannot be overemphasised. Finite element method was employed in the computation of magnetic field as far back as 1970 [15]; it has been used to design and analyse the structures of an innovative refrigerated container by Sepe et al in 2015 [16]. Also, using FEA simulations, by comparing the mould temperature of different cooling channel layouts, the design of conformal cooling channels was optimised [17]. The major challenge in optimising a model is effectively reducing cost, material and weight while improving strength performance, and life of components without compromising the effectiveness [18]. It is therefore appropriate to deploy finite element methods in solving linear and non-linear field problems including simple and complex geometries [19].

There have been various investigations on different appropriate container design and behaviour analysis of containers using FEA by several authors [20]. However, the aim of this research is to carry out a static and fatigue analysis using finite element method on the load container of a low-cost vehicle for Nigerian rural farmers with specific objectives to determine and process results of stress, strain, displacement, and factor of safety of two loading conditions on the container.

\section{METHODOLOGY}

A finite element analysis (FEA) was carried out on the container of a modelled low-cost vehicle designed to carry a maximum load of about $320 \mathrm{~kg}$ by Abdurrahman and Yahaya [1]. The static analysis of the trailer container was based on two scenarios using the Solid works software. The first scenario was conducted fixing the trailer container frame from beneath (the frame surface resting on the chassis) and applying a load of 3,139.2 $\mathrm{N}$ directly on to the trailer container platform and the simulation was carried out. Figure 1 and Figure 2 shows the fixed position and area on which the load was applied respectively.

The second scenario as shown in Figure 3 was a scenario where the trailer container sidewalls were also subjected to some share of the applied load, since the sidewalls are also supporting the load inside the container. The results obtained (stress, strain, displacement and factor of safety) were collated and analysed to see how the models reacted to the applied load. The results obtained from the FEA simulation were analysed, to see if they are within the acceptable limit and determine if the design is prone to failure or not. 


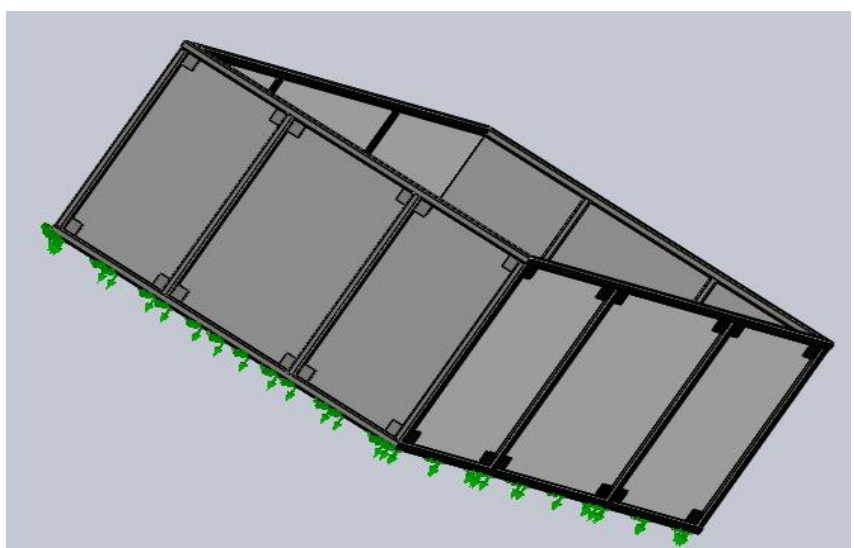

Figure 1: Application of fixture on container

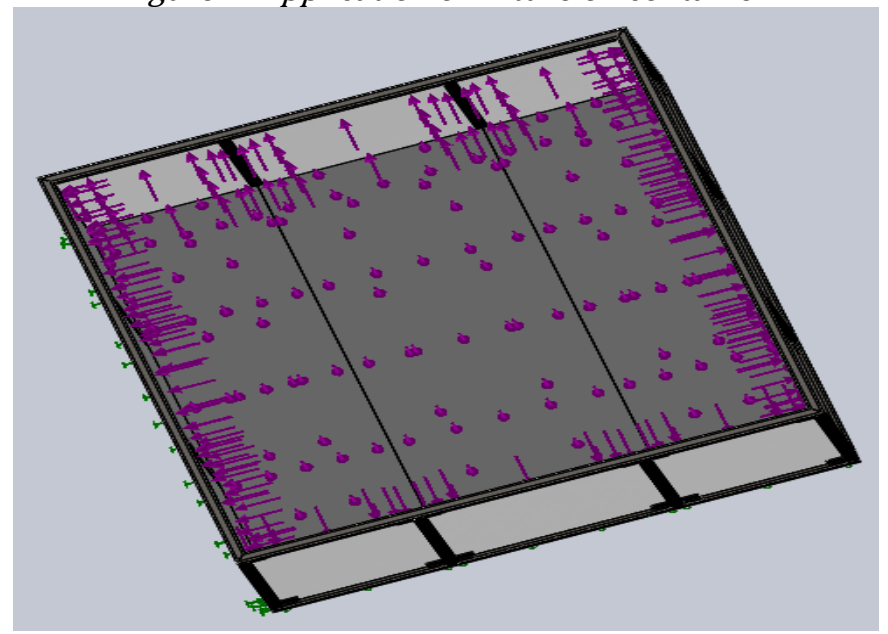

Figure 3: Second scenario load application on container

This was achieved by evaluating and analysing the maximum and minimum stresses, strain, deflection and factor of safety of the design based on applied load by setting the analysis units, creating study for the analysis units, assigning material to the model, meshing the model using a solid high quality mesh with maximum element size of $71.615 \mathrm{~mm}$, total nodes of 172,831 and total elements of 88,046 , applying static restriction to the end where the load container is attached to the vehicle chassis, applying the force magnitude and direction and running the analysis. Image of the meshed model is shown in Figure 4. The result was then checked and compared to the hand calculation employed in the design of the model. A conclusion was drawn out from the discussion and recommendations were made.

\section{RESULT AND DISCUSSION}

In the first scenario, Figure 5 shows the stress distribution of $54.6 \mathrm{~N} / \mathrm{m}^{2}$ minimum to $50,588,276$ $\mathrm{N} / \mathrm{m}^{2}$ maximum on the trailer container. Figure 6 shows the strain in the system and with a minimum strain of $2.54 \times 10^{-10}$ and maximum strain of $7.814 \times 10^{-5}$ and large percentage of the strain seen on the platform and the brackets holding it.

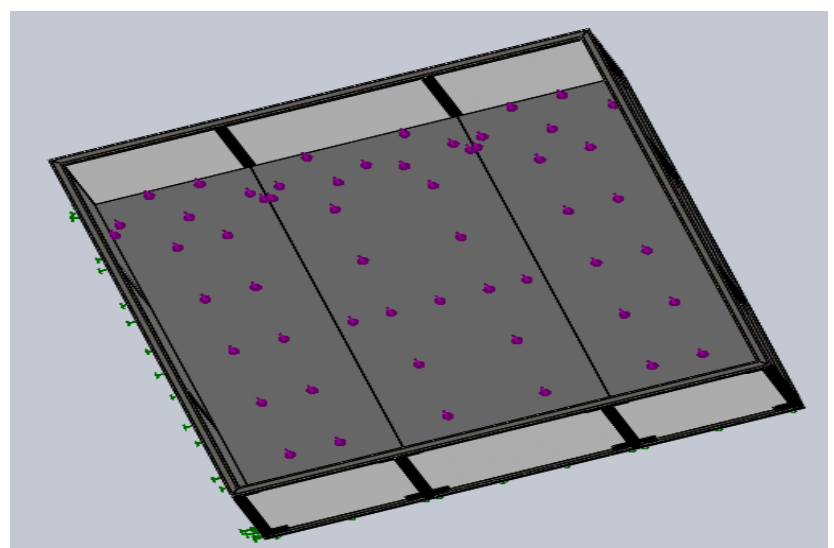

Figure 2: First scenario load application on container

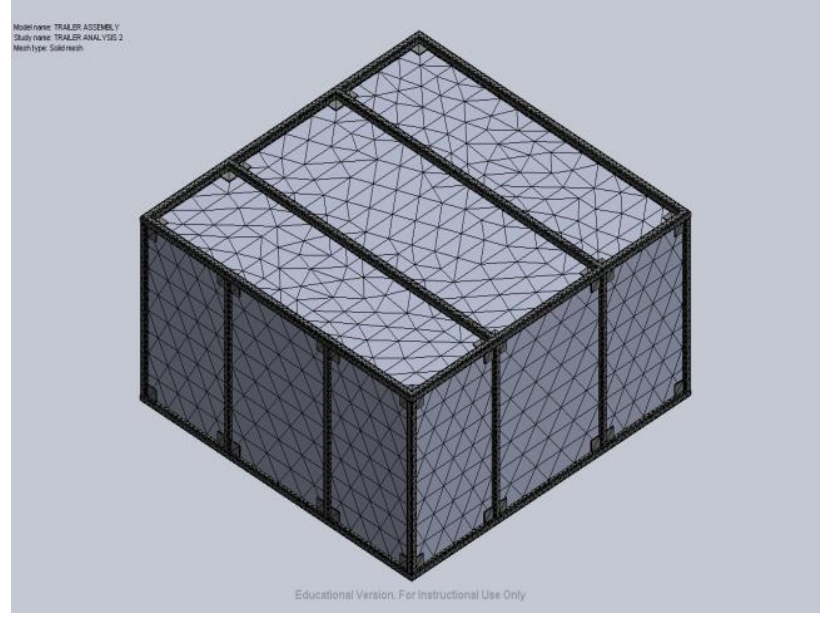

Figure 4: Meshed Model

In Figure 7 the maximum displacements move inward towards the centres of the platform separated by the frame columns and with maximum displacement of $1.31 \times 10^{-1} \mathrm{~mm}$. The last result obtained for first scenario as shown in Figure 8 gives a factor of safety of 4.4 for the trailer container.

These results revealed that the container is able to withstand the applied load, as the magnitude of strain and displacement on the platform are negligible and the factor of safety of the container is high. As a result, the container is not prone to serious deformation with respect to the applied load.

The second scenario obtained results in which the sidewalls of the container also support the applied load, revealed some differences from that of the first scenario. Figure 9 shows the stress distribution on the trailer container, with minimum stress of 3,102.7 N/ $\mathrm{m}^{2}$ and maximum of $34,078,660 \mathrm{~N} / \mathrm{m}^{2}$ and with some of the trailer frame member and brackets showing sign of high stresses. Figure 10 revealed strain distribution in the container with a minimum strain of $2.917 \times 10^{-8}$ and maximum strain of $7.113 \times 10^{-5}$ with the sidewalls also revealing strain pattern. 


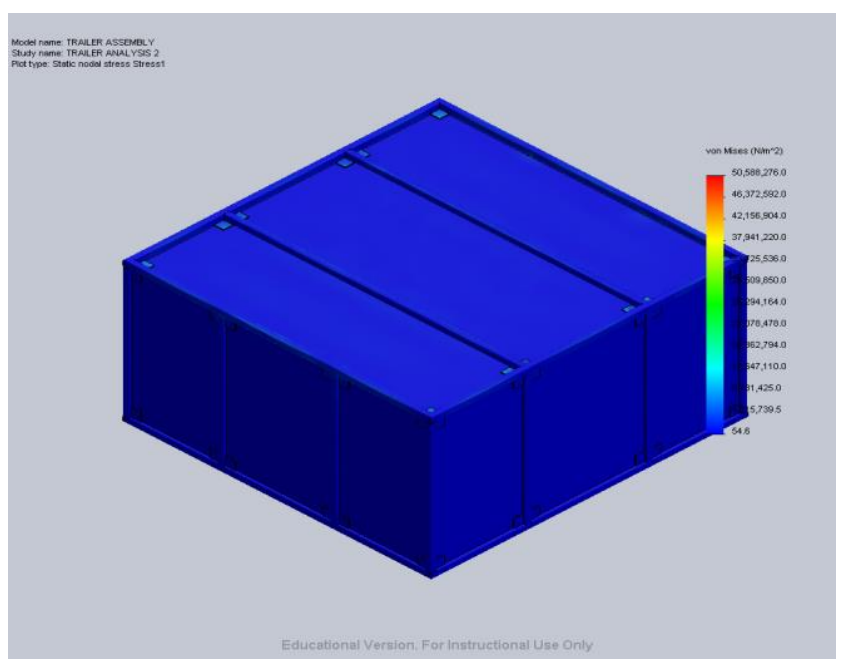

Figure 5: First scenario stress distribution on trailer container

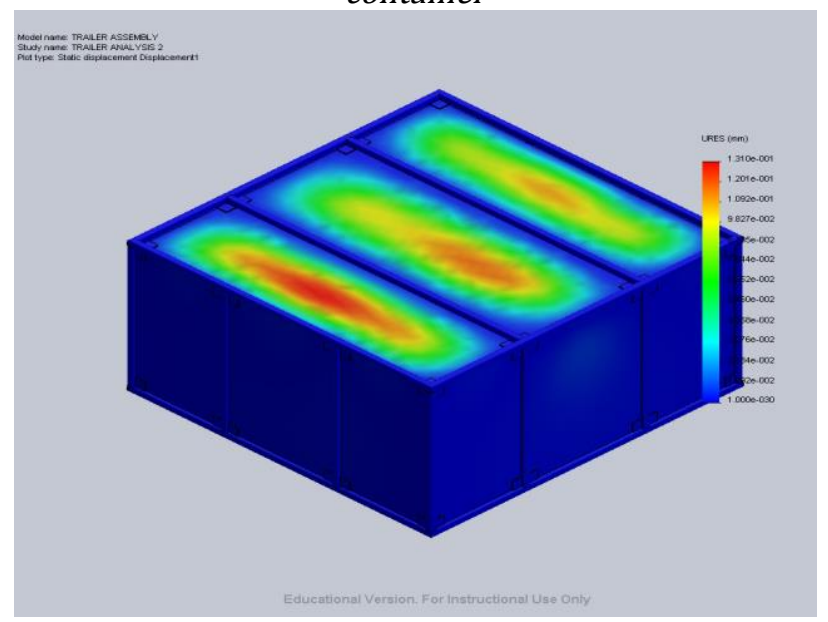

Figure 7: First scenario displacement distribution on trailer container

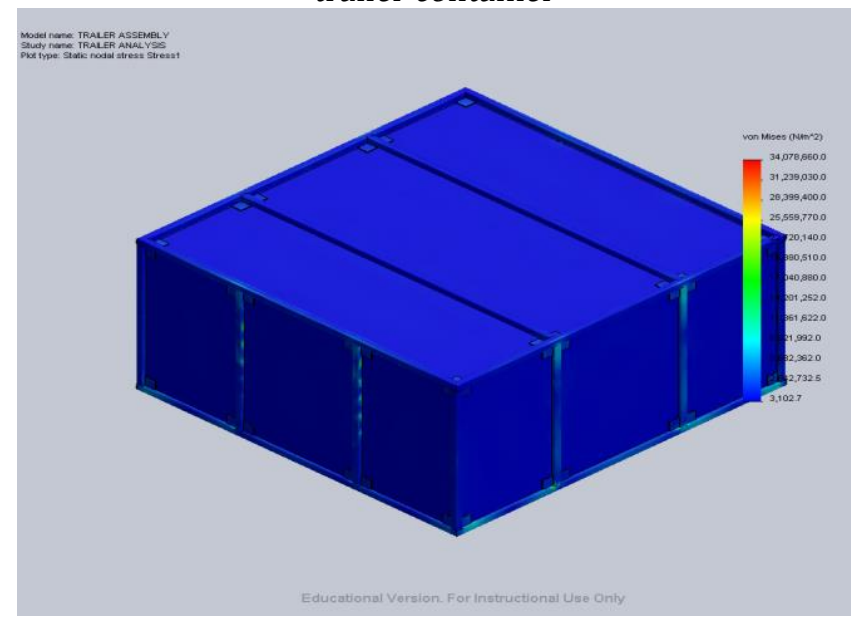

Figure 9: Second scenario stress distribution on trailer container

Figure 11 shows the displacement in the trailer container having maximum displacement of $1.361 \times 10^{-1}$ $\mathrm{mm}$ with high part of the displacement seen on the container sidewalls. Figure 12 shows most part of the trailer container in red, gives a factor of safety of 4.7

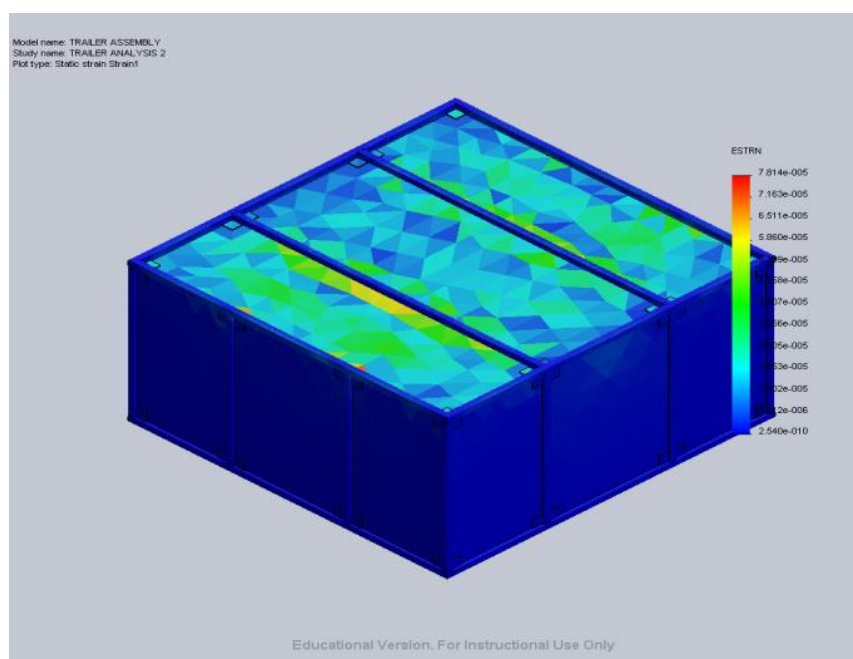

Figure 6: First scenario strain distribution on trailer container

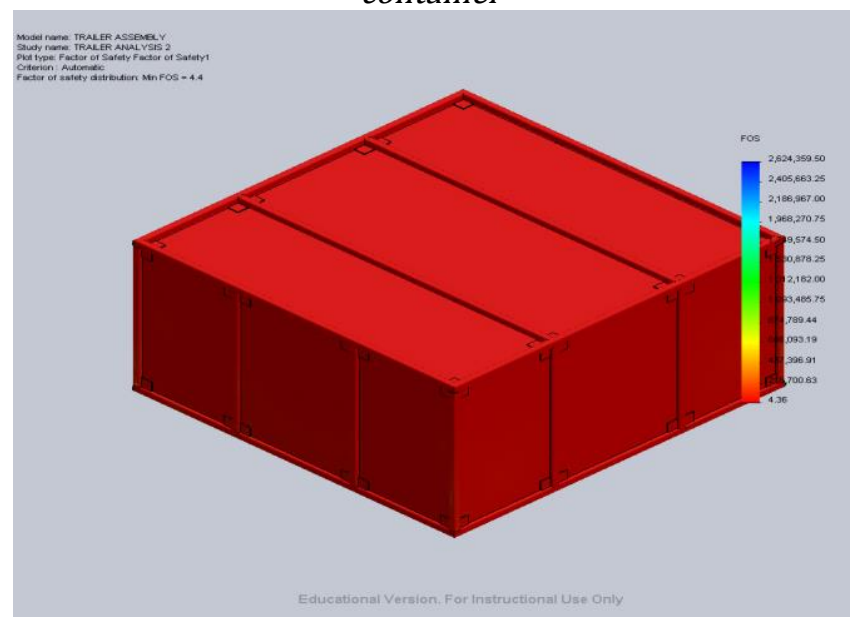

Figure 8: First scenario factor of safety of trailer container

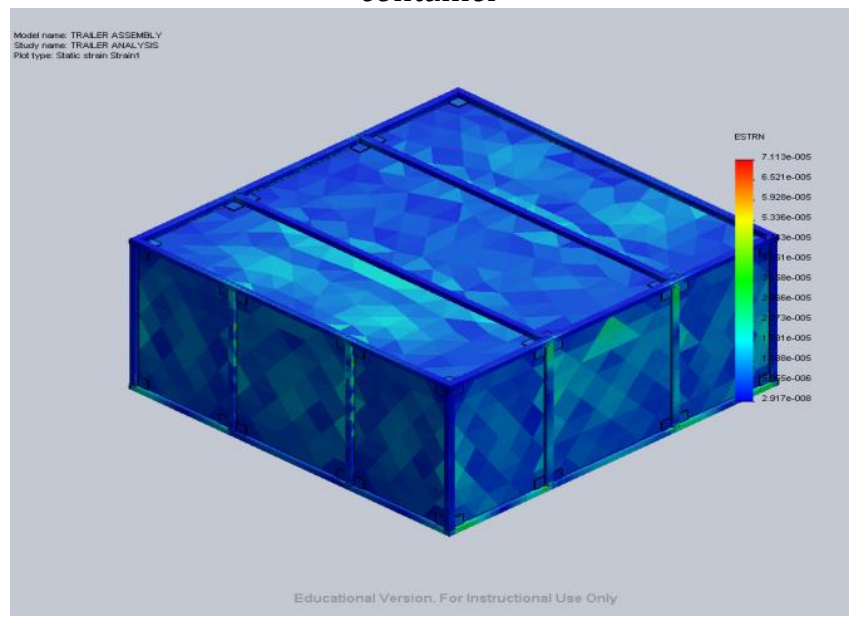

Figure 10: Second Scenario strain distribution on trailer container

with some yellowish-green doted area on the frame members showing higher factor of safety

The results in the second scenario show that there is reduction in the stress, strain and displacement on the container, owning to the fact that the trailer container 
sidewalls share part of the load and led to an increase in the factor of safety value from 4.4 to 4.7 . The results in the two scenarios also indicate that the container had been well designed and it is not prone to any sort of serious deformation as long as the weight of load carried does not exceed 3,139.2 N.

Table 1 shows some of the results obtained from both hand calculation and the simulated model analysis of the trailer platform/container. From the table, the hand calculated results of stresses and strains all fall within the minimum and maximum ranges of the simulated model analysis results. This shows the container has been designed to withstand subjected loads as defined by the designers [1].

\section{CONCLUSION}

The analysis results obtained for the trailer container in the two scenarios show that the trailer container will definitely withstand the load of 3,139.2 $\mathrm{N}$ it is subjected to. In the first scenario, the maximum stress, strain, and displacement experienced in the container are seen on the platform carrying the entire load. The platform was able to withstand the load as the maximum displacement is $0.131 \mathrm{~mm}$, which is negligible and with the trailer factor of safety of 4.36. This is high enough to sustain the load. There was a reduction in the amount of maximum stress experienced by the container in the second scenario since the sidewalls also takes part of the load. This accounted for the

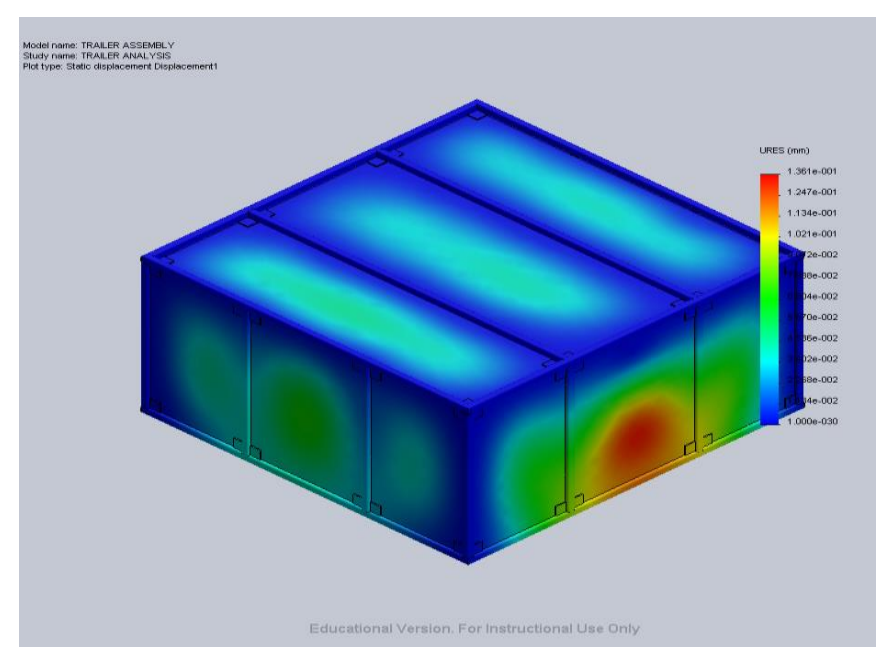

Figure 11: Second scenario displacement distribution on trailer container displacement, though with a negligible increase of $0.005 \mathrm{~mm}$, witnessed in the sidewalls and an increase in factor of safety of 4.65 in the trailer container.

\section{REFERENCES}

[1] Abdulrahman, K. O. and Yahaya, S. A., "Design of Low-Cost Vehicle for Nigerian Rural Farmers for Transportation of Farm Produce," J. Res. Civ. Eng., Vol. 13, Number 2, 2016.

[2] Olawepo, R. A. and Fatulu, B., "Rural Women Farmers and Food Productivity in Nigeria: An Example from Ekiti Kwara, Nigeria," Asian Soc. Sci., Vol. 8, Number 10, 2012.

[3] Kassali, R., Ayanwale, A. B., Idowu, E. O., and Williams, S. B., "Effect of Rural Transportation System on Agricultural Productivity in Oyo State, Nigeria," J. Agric. Rural Dev. Trop. Subtrop., Vol. 113, Number 1, pp. 13-19, 2012.

[4] Agbo, C. O. A., "A critical evaluation of motor vehicle manufacturing in Nigeria," Niger. J. Technol., Vol. 30, Number 1, pp. 8-16, 2011.

[5] Suh, N. P., "Designing and engineering through collaboration and negotiation," Int. J. Collab. Eng., Vol. 1, 2009, pp. 19-37.

[6] Zhuming, B., "Applications-Solid Mechanics Problems," in Finite Element Analysis Applications, Elsevier,, pp. 281-339, 2018.

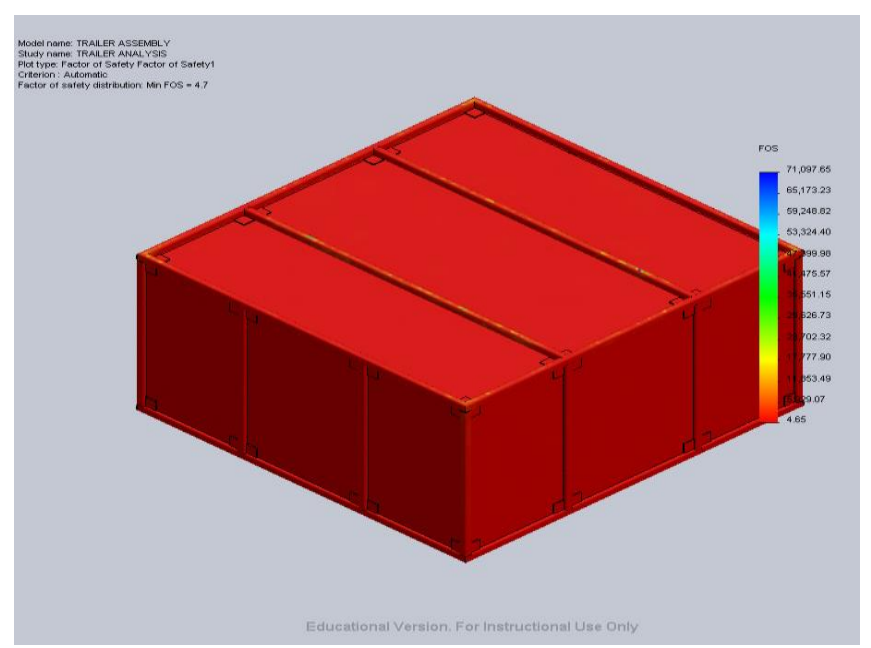

Figure 12: Second scenario factor of safety of trailer container

Table 1: Results on hand calculation and simulated model analysis

\begin{tabular}{llll}
\hline & Hand Calculation & Min. Simulated Result & Max. Simulated Result \\
\hline Stress on Platform/container & $3467.879 \mathrm{~N} / \mathrm{m}^{2}$ & $54.6 \mathrm{~N} / \mathrm{m}^{2}$ & $50588276 \mathrm{~N} / \mathrm{m}^{2}$ \\
Strain on Platform/container & $5.026 \times 10^{-7}$ & $2.54 \times 10^{-10}$ & $7.814 \times 10^{-5}$ \\
\hline
\end{tabular}


[7] Langley, J., Janson, R., Wearn, J., and Yoxall, A., "Inclusive' design for containers: improving openability," Packag. Technol. Sci., Vol. 18, Number 6, Nov, pp. 285-293. 2005.

[8] Puckett, A. A., "FEA stress analysis for SAFKEG 2863B," Los Alamos, NM, Jul. 1997.

[9] Abdulkarim, K., Abdulrahman, K., Ahmed, I., Abdulkareem, S., ADEBISI, J., and Harmanto, D., "Finite Element Analysis of Mini Combined Harvester Chassis and Hitch," J. Prod. Eng., Vol. 20, pp. 48-54, 2017.

[10] Abejide, O. S. and Okoro, E. E., "Safety of Carbon Fibre Reinforced Plastic Hollow Sections in Compression," Niger. J. Technol., Vol. 35, Number 4, pp. 739-753, 2016.

[11] Fahy, M. and Tiernan, S., "Finite element analysis of ISO tank containers," J. Mater. Process. Technol., Vol. 119, Number 1-3, Dec, pp. 293-298. 2001.

[12] Farayibi, P. K., "Finite Element Analysis of Plastic Recycling Machine Designed for Production of Thin Filament Coil," Niger. J. Technol., Vol. 36, Number 2, pp. 411-420, 2017.

[13] Reina, J., "Lab 7: Structural Analysis of a Bicycle Frame using Finite Element Techniques.," 07. [Online]. Available: http://www.justinreina.com/portfolio/ME 354 Bicycle lab.pdf. [Accessed: 04-Dec-2017].
[14] Sun, H., Luo, Y., and Yang, X., "Portable tank and tank container for liquefied gas transportation," US 2008/0067.178 A1, 12-Sep-08. 2008.

[15] Chari, M. V. K. and Silvester, P., "Analysis of turboalternator magnetic fields by finite elements," IEEE Trans. Power Appar. Syst., Vol. PAS-90, Number 2, pp. 454-464, 1971.

[16] Sepe, R., Armentani, E., and Pozzi, A., "Development and stress behaviour of an innovative refrigerated container with PCM for fresh and frozen goods," Multidiscip. Model. Mater. Struct., Vol. 11, Number 2, Aug, pp. 202215. 2015.

[17] Bertus, V. A., Combrinck, J., Booysen, G. J., and de Beer, D. J., "Direct metal laser sintering, using conformal cooling, for high volume production tooling," Vol. 28, Number 4, pp. 170-182, 2017.

[18] Patel, H., Panchal, K. C., and Jadav, C. S., "Structural Analysis of Truck Chassis Frame and Design Optimization for Weight Reduction," Int. J. Eng. Adv. Technol., Vol. 2, Number 4, pp. 665-668, 2013.

[19] Abunike, E. C., Okoro, O. I., and Umoh, G. D., "Steady and Dynamic States Analysis of Induction Motor: FEA Approach," Niger. J. Technol., Vol. 36, Number 4, pp. 1202-1207, 2017.

[20] Han, J. and Park, J. M., “Finite element analysis of vent/hand hole designs for corrugated fibreboard boxes," Package. Technol. Sci., Vol. 20, Number 1, pp. 39-47, 2007. 